\title{
Artists, audiences and wellbeing: An economic analysis
}

\author{
Marie Briguglio · Gilmour Camilleri · Melchior Vella
}

\begin{abstract}
We set out to examine the relationship between cultural engagement and wellbeing in a European Union state, Malta. We specify a conceptual model of wellbeing, captured by self-assessed life satisfaction as the predicted variable. Armed with a rich dataset $(n=1,125)$, drawn from a nationally representative sample, we construct variables that capture the diverse forms of cultural participation including a variable that identifies artists. We test three hypotheses, namely that passive cultural participation (audience) is positively associated with life satisfaction, that active (productive) cultural participation is positively associated with life satisfaction, and that artists have a higher level of life satisfaction, all else being equal. We find that both active and passive participation activities are associated with higher levels of life satisfaction; that active participation (including production, donation and travel) manifests a stronger relationship with life satisfaction than passive participation; and that life satisfaction is higher among those who identify as artists even after the effects of all other control variables are parsed out. This being the first nationally representative study on life satisfaction in Malta, the study makes a useful contribution in this regard, finding that factors like employment, health, engagement in sport, politics, religion, environment, as well as region of residence and migration are all significant correlates of life satisfaction.
\end{abstract}

Keywords: cultural engagement, artist, life satisfaction, Malta

\section{Introduction}

The relationship between wellbeing and engagement in cultural activities has received increasing attention in recent years. But the quantitative analysis of the relationship is challenging for several reasons. Firstly, it requires measurement of two key variables, neither of which are easy to define, still less measure. What constitutes cultural engagement (whether as audience or artist) remains a contested issue (Laitio, 2012), and one that can take different interpretations depending on context (Walker et al., 2002; Briguglio and Sultana, 2017). What constitutes wellbeing is also a question that has received scholarly attention for centuries, and remains a subject of controversy (Diener et al., 1999; Briguglio 2019). Even when quantitative data on both variables is available, the scientific analysis of the relationship between the two requires the researcher to avail of data on a range of other control factors that could come into play. In what follows, we set out to examine the determinants of life satisfaction and the role of cultural engagement in a European Union country, Malta. Here a Cultural Participation Survey conducted by the National Statistics Office (NSO, 2017) provides the data necessary not only to estimate the country's first wellbeing model based on nationally representative data, but also to focus on the effects of cultural engagement using a remarkably rich set of variables. These variables include those that identify 
active (productive) cultural participation, passive participation (as audience) as well as those that distinguish artists from non-artists on the Islands.

\subsection{Defining artists and audience engagement}

Defining what constitutes an artist can be complex for it brings up the ontological issue of what inherently constitutes art and whether the artist has some special quality, capacity or gift to produce this (Mitchell and Karttunen, 1992; Lena and Lindemann, 2014). Bird (1979) argues that the social scientist should not evaluate or rank art in aesthetic terms, but should rely on objective facts. Bourdieu (1983) views the status of the artist as a functional one, advocating against defining boundaries of the art world. On the other hand, Becker (1984) relies on the existence of conventions to draw the line between an artist and everyone else. Mitchell and Karttunen (1992) operationalise the definition in various ways. Firstly, an artist can be a person who produces artistic work or carries out artistic activities, including artistic work, audience engagement, exhibits or disseminations, and commercial outcomes. Secondly, what distinguishes artists from others is their rights and obligations, special privileges or sanctions. Thirdly, one can rely on recognised bodies or legitimate colleagues, particularly given that the rise of copyright legislation has stimulated increased association and creation of artistic lobbies. The extent of diversity among artistic practitioners can, however, render such definitions problematic (Towse, 1996). A different way to define an artist is to rely on self-assessment. The UNESCO Recommendation concerning the Status of the Artist (1980) indeed considers an artist to be self-proclaimed: one may qualify as an artist if artistic creation is an essential part of one's life. This approach is extensively used in cultural studies when wide sampling frames are used, and helps to spot emerging artists (Karttunen, 1998). While Frey and Pommerehne (1989) point out that one can hardly be considered as artist unless one's work is exhibited or published, Towse (1996) argues that self-definition avoids elitism. The extent to which artists (or non-artists) are able to define themselves can also be influenced by the sense of achievement that comes with the title (Craig, 2007).

In terms of cultural engagement more broadly, the UNESCO Framework for Cultural Statistics considers flows in the domain of culture to encompass production, dissemination, transmission, consumption, creation, exhibition and participation (UNESCO, 2009). Such flows, in turn, can occur in the domains of Visual Arts and Crafts, Performance and Celebration, Cultural and Natural Heritage, Books and Press, Audio-visual and Interactive Media, Design and Creative Services and Intangible Cultural Heritage (UNESCO, 2009). It is also possible to distinguish the extent and manner in which one engages in such activities. One key distinction is between those who create or produce a cultural product, and those who consume it (audiences). Typically, the latter far outnumber the former (European Commission, 2012). Engagement can also include more detached forms, such as through financial contributions or volunteering in the production of an activity (Walker et al. 2002). The measurement of cultural engagement has made possible an understanding of the diversity in extent to which it is undertaken and promoted by governments across different countries, and indeed within them (Belfiore and Bennett, 2007).

\subsection{The relationship between cultural engagement and wellbeing}

There is a growing body of evidence that cultural engagement can positively affect wellbeing, diversely defined (e.g. Blessi et al., 2014; Ceci et al., 2015). Insights as to the mechanisms at play include the prospect that cultural engagement can improve skills, cultural capacity and creativity (Hetland, 2000). Active engagement can lead to the development of new skills and contribute to 
positive public recognition, thereby enhancing self-concept and the sense of life control (Fiske, 1999; Fancort et al., 2019). Cultural engagement can also foster social bonds (Grossi et. al., 2011). Such engagement appears to also be associated with better physical health (Baklien, 2000). The positive use of art has also been noted in clinical outcomes, reducing hospital stays and offsetting the need for medication to induce sleep (Stuckey and Nobel, 2010). Work among children has found that those who have an arts-integrated curriculum, and that engage in an arts class, tend to do better at school (Fiske, 1999; Hetland and Winner, 2001). Among youths, the evidence also suggests positive association between engagement in traditional cultural activities and life satisfaction (Briguglio and Sultana, 2017). Among seniors, collective creative engagement has resulted in improvement in perceived overall health, experience of pain, and sense of community (Phinney et al., 2014).

One line of investigation in this literature is on the distinction between active versus passive (audience) engagement. Some studies (e.g. Briguglio and Sultana, 2017) find stronger effects from active participation. Similarly, some note that when people manage their cultural initiatives, they tend to report more enjoyable experiences (Baklien, 2000). Day and Devlin (1998) also find that volunteer work in arts and culture increases the individuals' earnings as a result of new skills and business contacts, and of the favourable signal sent to employers. Others trace wellbeing effects from simply attending cultural events (Blanchflower, 2009), with some authors arguing that simple exposure to art may result in enhanced knowledge and cultural capital (Hetland, 2000). Another distinction is that between activities that are social and those that require solitude. The latter have been found to be negatively correlated with wellbeing (Long and Averill, 2003). Michalos (2005) notes that, while art-related activities tend to contribute positively to wellbeing overall, their effects are smaller than those of other determinants like self-esteem and social interaction. Similar observations are made by Golloway, whose 2007 meta-analysis also notes that findings are not generalisable across cultural forms, project types and individuals (Golloway, 2007).

There is also a small literature that focuses on the wellbeing of artists themselves. Given the association between engaging in artistic activities and wellbeing, it is not surprising that some studies indicate that artists are happier than others (Bille et al., 2013). Social support and shared passions can also be underlying reasons for higher wellbeing among artists (Willis et al., 2019). Csikszentmihalyi (2000) observed that artists are likely to be driven more by the intrinsic rewards rather than the external rewards like money, praise, and promotion. Higher job satisfaction among artists could also be attributed to higher self-employment rate, increased variety of work as well as on-the-job training (Steiner and Schnieder, 2013). Nonetheless, there are also factors associated with being an artist that can have negative effects on wellbeing. Being an artist can be linked with certain negative organisational, social and emotional demands, such as sustained physical and mental stress, lack of job security and transient organisational affiliations (Robb et al., 2018). As a job, that of an artist can come with significant commitment, high effort and low reward (Burgoyne et al., 1999). At times there is exorbitant competition (Perkins et al., 2017). There are also documented associations between being an artist and being unemployed (Alper and Wassall, 2006), having a tenuous financial situation (Schulz et al., 1997), or having supplement one's income with undesirable work (Stack, 2010). Poor mental and physical health can also characterise the demographic of artists (Waddell, 1998; Kenny et al., 2016). Such conditions can act as moderating factors which suppress wellbeing among artists. 


\subsection{Context}

Our study takes place in Malta, a small island state which forms part of the European Union. Malta (and its sister island Gozo) offers an ideal context for the study given the recent surge in attention to cultural participation, encompassing institutional development, budgetary provision and data collection. A National Cultural policy was launched in 2011 (PSTEC, 2011), which aimed to improve cultural governance structures and international cultural cooperation, professionalise artists and develop cultural and creative industries, among other goals. A revamped legal structure saw the reorganisation of the Arts Council Malta (Act 15 of 2015) and a new strategy aimed at bringing the arts closer to people (ACM, 2015). Malta's cultural policy is also guided by the European Commission (2012) Work Plan for Culture. The years around the data collection period saw an increase in government expenditure in Malta, such that arts expenditure a percentage of GDP was higher than that of the EU-28 average in 2015. Various funding programmes were initiated by the Arts Council (MFIN, 2017) and in 2018, Valletta was named the European Capital of Culture.

Notwithstanding this effort, the Maltese continue to exhibit low levels of participation in several domains of art and culture, both as audiences and artists, except in traditional (folkloristic) events like village festivals (Briguglio and Sultana, 2015, 2017). When community patterns of cultural participation were first systematically assessed in a nationally representative survey (NSO, 2012), the findings revealed that attending art exhibitions, dance and theatre were highly unpopular activities (NSO, 2012). Productive, or active participation was mainly prominent in traditional village festivals celebrating a patron saint, or Carnival. These findings were echoed by the European Commission's 2013 evaluation of participation among member states (European Commission 2013). In other activities, lack of interest followed by lack of time seem to be the main cause of low attendance for much of the population, except for young people, for whom cost and lack of choice were also barriers (European Commission, 2013). In 2016, Eurostat again reported that only some 13\% of respondents from Malta confirmed that they actively engaged in some form of artistic activity such as singing, acting, photography, filmproduction, dancing, playing a musical instrument (Eurostat, 2016). That same year, Malta's National Statistics Office embarked on a large and detailed data collection process intended to understand the variation in cultural uptake across the islands (NSO, 2017). This data forms the basis for our analysis.

\section{Method}

\subsection{Model and hypothesis}

We follow others in measuring wellbeing through individuals' subjective assessment of happiness or life satisfaction on an ordinal scale (e.g. Blanchflower, 2009; Briguglio, 2019). We specify a conceptual model whereby this is expressed as a function of cultural engagement (our phenomenon of interest) and other known factors. There is vast literature on such determinants of life satisfaction which encompass a wide range of such factors like health, employment, engagement in sport, religion, social interaction, the environment, political considerations as well as demographic considerations like marital status, education, gender and age (Briguglio 2019). We therefore specify Model A as follows:

Model A: $y_{i}=\mathbf{x}_{i}^{\prime} \beta+z_{i} \alpha+u_{i}$ 
where $y_{i}$ denotes the subjective wellbeing of an individual $i$. $\mathbf{X}_{i}$ is a vector of covariates, capturing the individual characteristics and control variables that are known to be relevant in the literature on wellbeing, $z_{i}$ is cultural engagement and $u_{i}$ is a stochastic error term, indexed $i$ for the individual. Our intent is to test the following hypotheses:

Hypothesis 1: Active engagement in the arts is positively associated with life satisfaction.

Hypothesis 2: Audience engagement in the arts is positively associated with life satisfaction.

Hypothesis 3: Artists exhibit higher levels of life satisfaction, all other things held constant.

Table 1. Definition and description of variables

\begin{tabular}{|c|c|c|c|c|c|c|c|c|}
\hline Variable Name & Description & Mean & SD & Min & Max & $\begin{array}{l}\text { Artist } \\
\text { Mean }\end{array}$ & $\begin{array}{l}\text { Other } \\
\text { Mean }\end{array}$ & $\begin{array}{c}\text { (p- } \\
\text { value) }\end{array}$ \\
\hline Satisfy & Self-Assessed Life Satisfaction & 7.8 & 1.8 & 1.0 & 10.0 & 8.2 & 7.7 & 0.00 \\
\hline Artist & Artist (self-assessed) & 0.2 & 0.4 & 0.0 & 1.0 & & & \\
\hline Artist_A & Artist and in Active Employment & 0.1 & 0.3 & 0.0 & 1.0 & & & \\
\hline Artist_I & Artist and Inactive & 0.1 & 0.3 & 0.0 & 1.0 & & & \\
\hline Audience_NT & Audience Index (excl. Traditional) & 4.5 & 5.2 & 0.0 & 35.0 & 6.9 & 3.8 & 0.00 \\
\hline Audience_T & Audience Index (Traditional only) & 2.0 & 1.5 & 0.0 & 5.0 & 2.1 & 2.0 & 0.38 \\
\hline Audience & Audience Index (all) & 6.5 & 5.7 & 0.0 & 40.0 & 9.0 & 5.8 & 0.00 \\
\hline Audience Travel & Audience Travel Overseas Index & 1.1 & 1.9 & 0.0 & 9.0 & 1.6 & 1.0 & 0.00 \\
\hline Audience Festival & Festival attendance Index & 0.4 & 0.9 & 0.0 & 7.0 & 0.6 & 0.4 & 0.00 \\
\hline Participation_NT & Participation Index (excl. Traditional) & 1.3 & 2.4 & 0.0 & 20.0 & 3.0 & 0.9 & 0.00 \\
\hline Participation_T & Participation Index (Traditional only) & 0.5 & 1.3 & 0.0 & 10.0 & 0.8 & 0.4 & 0.00 \\
\hline Participation & Participation Index (All) & 1.8 & 3.0 & 0.0 & 24.0 & 3.9 & 1.2 & 0.00 \\
\hline Donation & Donation Index & 5.2 & 2.4 & 2.0 & 10.0 & 6.4 & 4.9 & 0.00 \\
\hline Illness & Respondent has health limitations & 0.2 & 0.5 & 0.0 & 2.0 & 0.2 & 0.3 & 0.37 \\
\hline Environment & Hobby/Interest Environment & 2.1 & 1.1 & 0.2 & 4.0 & 2.5 & 2.0 & 0.00 \\
\hline Sport & Frequency Sport & 1.7 & 1.7 & 0.0 & 4.0 & 2.0 & 1.6 & 0.00 \\
\hline Religion & Frequency Religious Activity & 2.0 & 1.5 & 0.0 & 4.0 & 2.2 & 2.0 & 0.03 \\
\hline Social & Index of socialising Friends/Family & 5.6 & 1.8 & 0.0 & 8.0 & 5.7 & 5.6 & 0.36 \\
\hline Political & Hobby Politics (Yes 1, No 0) & 0.3 & 0.4 & 0.0 & 1.0 & 0.3 & 0.3 & 0.12 \\
\hline Unemployment & Unemployed 1, All other 0 & 0.0 & 0.1 & 0.0 & 1.0 & 0.0 & 0.0 & 0.04 \\
\hline Education & Education (Bands) & 3.3 & 1.0 & 1.0 & 5.0 & 3.5 & 3.2 & 0.00 \\
\hline Marriage & Civil status (Married 1, All other 0) & 0.5 & 0.5 & 0.0 & 1.0 & 0.5 & 0.5 & 0.33 \\
\hline Gender & Gender (Female 1, Male 0) & 0.5 & 0.5 & 0.0 & 1.0 & 0.5 & 0.5 & 0.04 \\
\hline Age & Age brackets & 3.8 & 1.7 & 1.0 & 6.0 & 3.5 & 3.9 & 0.00 \\
\hline Region & District (Gozo 1, Malta 0) & 0.1 & 0.3 & 0.0 & 1.0 & 0.1 & 0.1 & 0.41 \\
\hline Abroad & Respondent lived abroad (Yes 1) & 0.9 & 0.3 & 0.0 & 1.0 & 0.9 & 0.9 & 0.59 \\
\hline
\end{tabular}

Note. $\mathrm{N}=1,125$ for All, N=241 for Artists and N=884 for non-Artists. Data source: (NSO, 2017).

\subsection{Data}

To test our hypotheses, we fit the model to data, employing the micro-data $(n=1,125)$ drawn from the Cultural Participation Survey conducted by Malta's National Statistics Office (NSO, 2017) which was gathered through face-to-face interviews between October and November 2016. ${ }^{1}$ Table 1 presents the data set we utilise in our analysis. The $y$-variable is measured by a standard life satisfaction question, "On a scale of 1 to 10, where 1 means very dissatisfied and 10 means very satisfied, can you please tell us how satisfied are you with your life these days?" To capture the

\footnotetext{
${ }^{1}$ Using sex, age and district of residence, the sample was tested in terms of representativeness of the Maltese population. The survey's margin of error at $95 \%$ confidence interval was $2.9 \%$.
} 
phenomenon of being an artist, we utilise responses to the question "Do you consider yourself to be an artist?". We note that a total of $21.4 \%$ of respondents considered themselves to be artists. This rate tallies with the figure published by the National Office of Statistics of Malta (NSO, 2017, p. 185), which collected the data according to the European Code of Practice. However, it is considerably higher than figures based on employment status (e.g. Eurostat, 2016). The difference is unlikely to be due to sampling error given the high confidence intervals reported by the NSO (NSO, 2017). Rather, it probably relates to the use of self-assessment as the method of identification. As discussed earlier, the term "artist" can be defined in various ways. Selfidentification arguably allows for the broadest of definitions, capturing respondents who practice or practiced any art form, whether as a hobby or as employment. Indeed, UNESCO (2019, p. 69) notes that, based on the analysis of submissions to the 2018 global survey concerning the status of artists, the actual population of artists is much higher than the population of employed artists. The former includes not only the latter, but also those in informal employment, amateurs and ordinary people who are involved in any form of artistic creation (Gruber, 2019).

Given the sheer breadth of questions pertaining to cultural and artistic participation in the survey, we set about constructing a number of composite indices that collapse engagement into diverse components. For passive participation in cultural events, we construct an index which sums up the unweighted frequency of attendance to cultural activities by respondents in various activities namely: theatre, live music, dance, artistic performances, art exhibitions, library, museums and historical sites over the preceding 12 months. We call this "Audience_NT" and find that it assumes a range from 0 to 35. Attendance was low on average with a mean of 4.5 and a median of 3.5. The share of those who said that they did not attend any of the named activities stood at $31.2 \%$. Given the prevalence of participation in traditional (folkloristic) cultural events, namely carnival festivities, processions, national holiday events, local council activities and parish church festivals and activities, the Cultural Participation Survey measures participation in these activities separately. This allowed us to create a second audience index "Audience_T". Here we note much higher participation: respondents attended just over 2 traditional events over the 12 months out of a maximum of 5 events. The distribution of this index is positively skewed with the lowest standard deviation amongst all the cultural indices. A composite audience index "Audience" was also constructed, being the summation of "Audience_T" and "Audience_NT".

Turning to productive engagement in the arts, we construct a similar index which sums up the extent to which respondents actively participate in a total of 18 activities presented to them by the survey, namely: ballet/dance, computer for artwork, crafts, play/drama, national feasts, films/videos as art, Good Friday, local council festivals, playing musical instrument, painting/drawing, activity in the local parish, photography as art, singing, active in carnival, storytelling, stories/plays and writing music. A score of 2 is assigned if the survey respondent actively participated in the last year, a score of 1 is assigned if he did so 1 to 3 years ago, and score of 0 otherwise. The index "Participation" reveals a skewed distribution and a mean score of 1.8. Over half of the participants did not participate in any activity at all. As we did with attendance to traditional evens, we also capture active involvement in traditional activities, using "Participation_T". We note that the majority $(71.2 \%)$ of the survey respondents did not participate in any traditional activity.

We were also able to construct a number of supplementary indexes. The variable "Travel", captures the extent of overseas travel related to art exhibitions, cinema/other artistic events, dance, historical sites, libraries, literature, concerts, museums, other and theatre. Nearly twothirds of the respondents returned a score of zero on this index. Given the burgeoning activities and national (non-parish) festivals in Malta, we examined participation in festivals specifically, 
creating the variable "Festivals". ${ }^{2}$ Respondents were mostly likely to have never been to a festival in the last year $(70.6 \%)$, while $21.3 \%$ of the respondents had attended one festival. The variable "Donation" measures the respondents' willingness to donate money or volunteer time to support an arts or cultural organisation, on a 5-point scale. High levels of disagreement were recorded in both willingness to volunteer time to support an arts or cultural organisation, and willingness to donate money to support an arts or cultural organisation. Two test variables were also created, accounting for artists who are not in active employment (e.g. retired, students, housewife or unemployed) and those who are active in employment (including self-employment). The latter amount to just over half of the artists.

The various co-determinants of life satisfaction are also summarised in Table 1 . The variable "Illness" measures responses to the question "Have you been limited because of a health problem in activities people usually do?". A composite index "Environment" gauges engagement with the natural environment derived from four questions in the survey (covering interest in green/environmental issues, wildlife/natural history, gardening and going into the countryside). The variable "Sport" reports frequency of sport or physical exercise in the past year, while the variable "Religion" captures the frequency with which respondents attend mass. The variable "Social" aggregates responses on the frequency of meeting with immediate family, and friends. The only data pertinent to political preferences in the survey was that on personal interest in politics, captured by the variable "Political". In the sample, $13.1 \%$ of the respondents had lived abroad and $8.4 \%$ resided in the sister island of Gozo. These distinctions were captured by the variables "Abroad" and "Region" respectively. Other demographics are captured by the variables "Unemployed", “Education", “Age”, "Marriage” and "Gender".

\section{Results}

\subsection{Profiling artists}

Prior to proceeding with a formal estimation of our models and analysis testing, we first examine the profile of Malta's self-assessed artists by comparing their means with those of respondents who did not self-assess as artists. As reported in Table 1, and as would be expected, artists are more likely to be engaged more actively and passively in cultural activities and tend to donate more time/money to an arts organisation. The analysis of means however, also reveals that the life satisfaction of artists is higher than that of non-artists. Relative to non-artists, artists tend to be younger, more educated, more engaged with the natural environment, exercise. These results are interesting in themselves as they refute some commonly held notions that link artists as unemployed persons, more susceptible to unemployment (Alper and Wassall, 2006; Bille et al., 2013) and with poor mental health (Stack, 2010; Waddell, 1998).

\subsection{Basic correlations}

We then proceed to examine basic correlations in our dataset. As expected, these reveal that the prevalence of illness is significantly higher (at the 95\% confidence level) among older respondents and lower among those with higher education. Being in employment and being engaged in sport return higher self-assessed health levels. Older people tend to have lower education and lower engagement in sport. Men tend to present in greater numbers among the employed, but in smaller numbers in church pews. Moreover, at the 95\% confidence level, life satisfaction correlates negatively with illness and unemployment and positively with education,

\footnotetext{
2 These include the Ghanafest, Malta International Arts Festival, Malta Jazz Festival, Notte Bianca, Three Palaces Festival, Valletta Green Festivals, Valletta International Baroque Festival and Valletta VIVA Festival.
} 
environmental, sport and cultural engagement. In turn, people who are engaged in culture tend to have better overall health and education, to be older and to be employed. They are also more likely to be environmental and undertake physical activity. Participation in traditional activities correlates with living in Gozo and with frequency of religious activity.

\subsection{Estimation of a model of life satisfaction for the Maltese Islands}

We next proceed to estimate a basic model with life satisfaction as the outcome variable. In such a model the fitted parameters reveal the relationship of each variable on self-reported life satisfaction after taking into consideration the effects of other control variables. Given the nature of our dependent variable, we employ an ordered logit model. Here a significant positive (negative) coefficient implies that a one-unit increase in the independent variable increases the log-odds of being in a higher (lower) level of life satisfaction. Robust standard errors are reported in parentheses to address the possibility of heteroscedasticity, this being frequently observed in cross-sectional datasets. ${ }^{3}$

We start by estimating Model 1, which explores the correlates of life satisfaction in the Maltese Islands without any arts variables included. The results here (see Table 2 below) broadly confirm that life satisfaction in Malta responds to phenomena as those observed in the wider literature. As in other contexts, we note that life satisfaction in Malta is negatively related to being unemployed, to illness and to having lived abroad (e.g. Grossi et. al., 2012; Frey and Stutzer, 2000), but positively related to sports (e.g. Netz et al., 2005), to environmental engagement (e.g. Brereton et al., 2008) and religious participation (e.g. Stark and Maier, 2008). We also note a negative coefficient on political engagement in contrast with mainstream findings (e.g. Helliwell and Huang, 2008), possibly due to the way political preferences are measured in this survey. We find that people living on the island of Gozo report higher levels of life satisfaction. Age, gender, and social marital status add little further explanatory power. Though the pseudo R-squared is low (typical of studies utilising data at the level of individual respondents), the variables in the specification explain the variance sufficiently to comfortably reject the null hypothesis that there is no effect by the independent variables taken together.

\subsection{Testing hypotheses on artists and the culturally engaged}

We now factor in variables for cultural engagement. To test our hypothesis that active involvement is positively associated with wellbeing, we extend the model by using the variable "Participation" (Model 2). We note that the active participation variable returns a strong and positive coefficient.

The likelihood ratio test also confirms that the inclusion of active participation results in a statistically significant improvement in the general fit of the model when compared to Model 1. This is in line with literature which contends that active engagement can be a positive determinant of wellbeing (e.g. Barklien, 2000). On the basis of these findings we therefore find some support for our Hypothesis 1, namely that active participation is associated with higher levels of life satisfaction. We contrast this with the variable that indexes passive participation (Model 3). While a unit increase in "Participation" is significantly associated with a higher probability of observing higher states of life satisfaction, the marginal effect of "Audience" for

\footnotetext{
${ }^{3}$ All the produced tables present the results of the coefficients in terms of odds ratio.
} 
the same category does not do so within acceptable levels of confidence. ${ }^{4}$ These findings suggest no support for Hypothesis 2 namely that passive participation is associated with higher levels of life satisfaction. Contrary to some studies which find that simply attending cultural events can improve wellbeing (Blanchflower, 2009), we find no such relationships in this analysis.

\section{Table 2. Determinants of wellbeing}

\begin{tabular}{|c|c|c|c|c|}
\hline \multicolumn{2}{|c|}{ MODEL } & 1 & 2 & 3 \\
\hline \multicolumn{2}{|c|}{ Unemployed } & $-1.36^{* *}$ & $-1.29^{* *}$ & $-1.34^{* *}$ \\
\hline \multicolumn{2}{|c|}{ Social } & 0.03 & 0.02 & 0.02 \\
\hline \multicolumn{2}{|c|}{ Political } & $-0.23^{*}$ & $-0.27^{* *}$ & $-0.24^{*}$ \\
\hline \multicolumn{2}{|c|}{ Environmental } & $0.17^{* * *}$ & $0.16^{* * *}$ & $0.16^{* * *}$ \\
\hline \multicolumn{2}{|c|}{ Region } & $1.19^{* * *}$ & $1.17^{* * *}$ & $1.17^{* * *}$ \\
\hline \multicolumn{2}{|c|}{ Lived Abroad } & $-0.39 * *$ & $-0.40^{* *}$ & $-0.39^{* *}$ \\
\hline \multicolumn{2}{|c|}{ Married } & 0.20 & 0.21 & 0.20 \\
\hline \multicolumn{2}{|l|}{ Gender } & -0.11 & -0.12 & -0.12 \\
\hline \multirow[t]{2}{*}{ Illness } & Limits & $-0.52^{* * *}$ & $-0.53^{* * *}$ & $-0.53^{* * *}$ \\
\hline & Limits+ & $-0.85^{* * *}$ & $-0.86^{* * *}$ & $-0.84^{* *}$ \\
\hline \multirow[t]{4}{*}{ Sport } & Annual & 0.44 & 0.37 & 0.41 \\
\hline & Monthly & -0.27 & $-0.30^{*}$ & $-0.29^{*}$ \\
\hline & Weekly & $0.32^{* *}$ & $0.28 *$ & $0.27^{*}$ \\
\hline & Daily & $0.34^{* *}$ & $0.32 * *$ & $0.30^{* *}$ \\
\hline \multirow[t]{4}{*}{ Religion } & Annual & 0.02 & 0.03 & 0.03 \\
\hline & Monthly & $0.40^{*}$ & 0.40 * & $0.39^{*}$ \\
\hline & Weekly & 0.08 & 0.07 & 0.07 \\
\hline & Daily & $0.47^{* *}$ & $0.43^{*}$ & $0.44^{*}$ \\
\hline \multirow[t]{4}{*}{ Education } & Primary & 0.52 & 0.51 & 0.53 \\
\hline & Second & 0.48 & 0.45 & 0.46 \\
\hline & Post-Sec & 0.64 & 0.61 & 0.60 \\
\hline & Tertiary & 0.73 & 0.66 & 0.65 \\
\hline \multirow[t]{5}{*}{ Age } & $25-34$ & 0.11 & 0.17 & 0.15 \\
\hline & $35-44$ & 0.12 & 0.18 & 0.15 \\
\hline & $45-54$ & 0.00 & 0.09 & 0.04 \\
\hline & $55-64$ & 0.03 & 0.13 & 0.10 \\
\hline & $65+$ & -0.07 & 0.03 & 0.01 \\
\hline \multicolumn{2}{|c|}{ Participation } & & $0.05^{* *}$ & \\
\hline \multicolumn{2}{|c|}{ Audience } & & & 0.02 \\
\hline \multicolumn{2}{|c|}{ Log likelihood } & -2005.96 & -2003.04 & -2004.58 \\
\hline \multicolumn{2}{|c|}{ Pseudo R2 } & 0.03 & 0.03 & 0.03 \\
\hline
\end{tabular}

Note. The table reports coefficient scales in log odds; ${ }^{* * *},{ }^{* *},{ }^{*}$ denotes significance at the $1 \%, 5 \%$, and $10 \%$ level respectively; In all models N=1125 and Prob>ch2 0.00; For the variables Illness, Sport, Religion and Education, the base category is None; for the variable Age the base category is 16-24; Data source: (NSO, 2017).

We delve deeper into this finding by parsing out the effect of participation in traditional events, these being the more popular kinds of activities in Malta. Table 3 (below) reports the results on

\footnotetext{
${ }^{4}$ Comparing the coefficients of active and passive participation is not straightforward as they have different means and standard deviations. We standardize both independent variables and then compare the coefficients. The estimated coefficient on PART_ALL and AUDI_ALL are 0.075 and 0.055 , respectively. The significance levels do not change.
} 
a series of test variables. ${ }^{5}$ We again note that active participation in traditional events, (Model 4) returns a positive and significant coefficient. These findings echo Briguglio and Sultana (2015) who find higher levels of wellbeing among young people who participate in village feasts, as well as other studies from Malta which revealed positive effects on social-connectedness from such activities (Cremona, 2014). When we parse out the role of participation in such traditional activities, we note they also appear to be responsible for driving the positive outcome on the aggregate participation variable. Active involvement in other (non-traditional) activities produces no significant returns (Model 5), once all other determinants are controlled for. Moreover, once we parse out attendance to traditional events (Model 6) from others (Model 7), we also find a significant and positive coefficient on the variable capturing mere attendance to traditional events, arguably explained by the fact that attendance is spread across a wider, and possibly, more fervent range of participants than other activities. This now provides some support to Hypothesis 2. Being an audience in traditional activities (like carnival festivities, processions, national holiday events, local council activities and parish church festivals and activities) is also positively and significantly associated with higher levels of life satisfaction, even once all other relevant factors are controlled for.

Table 3. Determinants of wellbeing - further tests

\begin{tabular}{|c|c|c|c|c|c|c|c|}
\hline MODEL & 4 & 5 & 6 & 7 & 8 & 9 & 10 \\
\hline Participation_T & $0.16^{* * *}$ & & & & & & \\
\hline Participation_NT & & 0.03 & & & & & \\
\hline Audience_T & & & $0.11^{* * *}$ & & & & \\
\hline Audience_NT & & & & 0.01 & & & \\
\hline Audience Travel & & & & & $0.07^{* *}$ & & \\
\hline Donation & & & & & & $0.07^{* * *}$ & \\
\hline Audience Festival & & & & & & & 0.02 \\
\hline Log likelihood & -1999.68 & -2005.43 & -2001.99 & -2005.52 & -2003.28 & -2001.23 & -2005.94 \\
\hline Pseudo R2 & 0.04 & 0.03 & 0.03 & 0.03 & 0.03 & 0.03 & 0.03 \\
\hline
\end{tabular}

Note. The models in this table were estimated with all the control variables presented in Table 2, namely marital status, gender, employment status, social, political and environmental engagement, sport, religious participation, illness, age and educational levels; The table reports coefficient scales in log odds; ${ }^{* * *},{ }^{* *}, *$ denotes significance at the 1\%,5\%, and 10\% level respectively; In all models N=1125 and Prob>ch2 0.00; Data source: (NSO, 2017).

We turn to the other variables which capture other forms of culture participation and estimate our basic model with the inclusion of these variables instead. In Table 3 (Model 8), we find that the overseas travel to consume culture is also positively associated with higher life satisfaction. Whether this is association is due to cultural consumption or overseas travel is not possible to parse out from the data. Persons who are either willing to donate money or volunteer time to support an arts or cultural organisation are also likely to have higher level of life satisfaction, as captured by the coefficient on "Donation". The estimated goodness-of-fit in Model 9 is among the highest of all the reported models, implying that it is a relevant correlate to life satisfaction, holding everything else constant. Once again, whether the effect is driven by the cultural component or the volunteering aspect poses an interesting question worth investigating further. Taken together, Model 8 and 9 yield further support to both Hypothesis 1 and 2, namely that

\footnotetext{
5 The models in Tables 3 and 4 here were estimated with all the control variables presented in Table 2. We present only the results of test variables but the coefficients on the remaining variables remain stable.
} 
whether as audience, or in more active roles, participation in culture is associated with higher levels of life satisfaction. As a final test, the index capturing participation in national festivals is utilised in Model 10, finding no statistically significant results.

In our final set of regressions, we examine the relationship between life satisfaction and being an artist, as measured by self-assessment. The headline results are reported in Table 4 (below). In Model 11 we find that, even when accounting for all the other factors that could be driving the higher levels of wellbeing, considering oneself to be an artist is associated with higher levels of life satisfaction. It can be reasonably argued that this is driven by the artists' higher involvement in active participation in the arts. To account for this possibility, we control for the effects by including the relevant indicators in Model 12 and 13. The estimated parameter on "Artist" remains statistically significant. We do however note that the variable "participation" loses its statistical significance when adding the variable "Artist", an outcome that suggests that the association between cultural engagement and life satisfaction may be driven by the subdemographic: artists. We also test whether being an artist and being employed manifests a different relationship with life satisfaction (Model 14 and 15). The results suggest that it is only among artists who are in active employment (including self-employment) that such a positive association with life satisfaction exists. Artists who are retired, students, housewives or unemployed do not manifest a higher probability of higher life satisfaction. We conclude that there is some evidence in support of Hypothesis 3, namely that being an artist is associated with higher levels of life satisfaction, at least among artists who are employed. These findings chime with those of others, as outlined earlier (e.g. Bille et al., 2013) including the possibility that artists reap personal gains from their work (Day and Devlin, 1998).

Table 4. Determinants of wellbeing - on being an "artist"

\begin{tabular}{lccccc} 
MODEL & $\mathbf{1 1}$ & $\mathbf{1 2}$ & $\mathbf{1 3}$ & $\mathbf{1 4}$ & $\mathbf{1 5}$ \\
\hline Artist & $0.38^{* * *}$ & $0.31^{* *}$ & $0.37^{* * *}$ & & \\
Participation & & 0.034 & & & \\
Audience & & & 0.01 & $0.34^{* * *}$ & \\
Artist_A & & & & 0.32 \\
Artist_I & -2002.05 & -2000.71 & -2001.92 & -2005.51 & -2006.16 \\
\hline Log likelihood & 0.03 & 0.03 & 0.03 & 0.03 & 0.03 \\
Pseudo R2 & & & & & \\
\hline
\end{tabular}

Note. The models in this table were estimated with all the control variables presented in Table 2, namely marital status, gender, employment status, social, political and environmental engagement, sport, religious participation, illness, age and educational levels; The table reports coefficient scales in log odds; ${ }^{* *},{ }^{* *},{ }^{*}$ denotes significance at the $1 \%, 5 \%$, and $10 \%$ level respectively; In all models $\mathrm{N}=1125$ and Prob>ch2 0.00; Data source: (NSO, 2017).

\section{Discussion and conclusion}

While our findings provide useful insights, a number of caveats need to be acknowledged. Firstly, our reliance on cross-sectional data limits our efforts to fully identify casual effect of artistic participation on wellbeing. Employing longitudinal data would allow for a better understanding of changes in wellbeing following external stimuli, including those that promote artistic engagement. As it is, we cannot fully exclude that causality may run in reverse direction: people with higher levels of life satisfaction may be more likely to become artists or to engage in cultural activities. Secondly, the estimated coefficients may also suffer from unobserved variable bias. For instance, there may be systematic differences in personality between artists and non- 
artists which may be driving the findings. This phenomenon could not be explored with the existing data. Thirdly, it must be noted that all data was collected from survey interviews and based on self-assessment. While this certainly creates some noise (and makes for a larger error) in the estimates, it is not likely to have created a systematic bias in our results.

Despite the shortcomings presented by cross-sectional survey-based data, we were able to test a very rich and unprecedented variety of variables capturing diverse forms of engagement in a single nationally representative sample. This being the first such dataset on wellbeing in Malta, our findings also make some contribution in this regard: we note that people in Malta report lower levels of life satisfaction if they are unemployed, limited by ill health, if they previously lived abroad or if they are interested in politics. Higher levels of wellbeing are reported among the more educated, physically active, religiously or environmentally engaged individuals and among those who live on the sister island of Gozo.

In relation to our main research question, our findings reveal that both active and passive participation are associated with higher levels of life satisfaction, at least in so far as we are dealing with the traditional (folkloristic) kinds of cultural participation. We further note that active participation (including production, donation and travel) manifests a stronger relationship with life satisfaction than does passive participation. Finally, we find that among the community of people that identify as artists, life satisfaction is also higher, particularly among those that who are in active employment.

\title{
Conflict of interest statement
}

The authors report no conflicts of interest.

\author{
Authors \\ Marie Briguglio \\ University of Malta \\ marie.briguglio@um.edu.mt \\ Gilmour Camilleri \\ University of Malta \\ Melchior Vella \\ University of Malta

\section{Publishing Timeline} \\ Received 21 April 2020 \\ Accepted 13 May 2020 \\ Published 1 October 2020
}

\section{References}

Alper, N. O., \& Wassall, G. H. (2006). Artists' careers and their labor markets. In V. A. Ginsburg, \& D.

Throsby (Eds.), Handbook of the economics of art and culture (pp. 813-864) Elsevier.

https://doi.org/10.1016/S1574-0676(06)01023-4

Arts Council Malta, (2015). Create 2020 strategy 2016-2020. Malta: Arts Council Malta.

https://www.artscouncilmalta.org/files/uploads/misc/English-Create2020_web.pdf. Accessed 22 April 2020.

Baklien, B. (2000). Culture is healthy. International Journal of Cultural Policy, 7(2), 235-257.

https://doi.org/10.1080/10286630009358145

Becker, H. S. (1984). Arts world. Berkeley: University of California Press. 
Belfiore, E., \& Bennett, O. (2007). Rethinking the social impacts of the arts. International Journal of Cultural Policy, 13(2), 135-151. https://doi.org/10.1080/10286630701342741

Bille, T., Fjællegaard, C. B., Frey, B. S., \& Steiner, L. (2013). Happiness in the arts-International evidence on artists' job satisfaction, https://doi.org/10.1016/j.econlet.2013.06.016

Bird, E. (1979). Aesthetic neutrality and the sociology of art. ideology and cultural production. In M. Barret, P. Corrigan, A. Kuhn, Wollf \& J. (Eds.), Ideology and cultural production (pp. 26-28). New York: St. Martin's.

Blanchflower, D. G. (2009). International evidence on well-being in measuring the subjective well-being of nations: National accounts of time use and well-being. Chicago: The University of Chicago Press.

Blessi, G. T., Grossi, E., Sacco, P. L., Pieretti, G., \& Ferilli, G. (2014) Cultural participation, relational goods and individual subjective well-being: Some empirical evidence. Review of Economics and Finance, 4(3), 33-46.

Burgoyne, S., Poulin, K., \& Rearden, A. (1999). The impact of acting on student actors: Boundary blurring, growth, and emotional distress. Theatre Topics, 9(2), 157-179. doi:10.1353/tt.1999.0011

Bourdieu, P. (1983). The field of cultural production, or: The economic world reversed. Poetics, 12(4), 311356. https://doi.org/10.1016/0304-422X(83)90012-8

Brereton, F., Clinch, J. P., \& Ferreira, S. (2008). Happiness, geography and the environment. Ecological Economics, 65(2), 386-396. https://doi.org/10.1016/j.ecolecon.2007.07.008

Briguglio, M., \& Sultana, A. (2015). The effect of the Maltese festa on well-being: An economic analysis, with a focus on youth participation. In A. Azzopardi (Ed.), Young people and the "festa" in Malta (pp. 51-73). Malta: Best Print Co. Ltd.

Briguglio, M., \& Sultana, A. (2017). Man cannot live on bread alone: Cultural participation and life satisfaction in Malta. In V. A. Cremona (Ed.), Capitalising on culture? Malta and the European Capital of Culture (pp. 15-36). Malta: Malta University Publishing.

Briguglio, M. (2019). Wellbeing: An Economics Perspective in Vella, S., Falzon, R., Azzopardi, A. (eds.) Perspectives on Wellbeing. Brill Sense, 2019. (pp. 145-157).

Ceci, M., \& Kumar, V. (2016). A correlational study of creativity, happiness, motivation, and stress from creative pursuits. Journal of Happiness Studies, 17(2), 609-626. https://doi.org/10.1007/s10902-015-9615y

Craig, A. (2007). Practicing poetry: A career without a job. In C. Calhoun, \& R. Sennett (Eds.), Practicing culture (pp. 31-64). New York: Routledge.

Cremona, V. A. (2014). When the saint comes marching out - the cultural playing of the Maltese festa. In V. A. Cremona, R. Hoogland, G. Morris \& W. Sauter (Eds.), Playing Culture (pp. 181-199). Netherlands: Brill Academic Publishers, Inc.

Csikszentmihalyi, M. (1990). Flow: The Psychology of Optimal Experience. New York: Harper and Row.

Day, K. M., \& Devlin, R. A. (1998). The payoff to work without pay: Volunteer work as an investment in human capital. The Canadian Journal of Economics / Revue Canadienne D'Economique, 31(5), 1179-1191. https://doi.org/10.2307/136465

Diener, E., Suh, E. M., Lucas, R. E., \& Smith, H. L. (1999). Subjective well-being: Three decades of progress. Psychological Bulletin, 125(2), 276-302.

European Commission. (2012). European agenda for culture work plan 2011-2014. Brussels: European Commission.

https://www.consilium.europa.eu/uedocs/cms_data/docs/pressdata/en/educ/117795.pdf. Accessed 22 April 2020.

European Commission. (2013). Special Eurobarometer 399: Cultural access and participation. Brussels: European Commission.

https://ec.europa.eu/commfrontoffice/publicopinion/archives/ebs/ebs_399_sum_en.pdf. Accessed 22 April 2020.

Eurostat. (2016). Culture statistics - 2016. Luxembourg: Eurostat.

Fancourt, D., Garnett, C., Spiro, N., West, R., \& Müllensiefen, D. (2019). How do artistic creative activities regulate our emotions? validation of the emotion regulation strategies for artistic creative activities scale (ERS-ACA). PloS One, 14(2), e0211362. https://doi.org/10.1371/journal.pone.0211362 
Fiske, E. B. (1999). Champions of change: The impact of the arts on learning. Washington, DC: Arts Education Partnership President's Committee on the Arts and the Humanities.

Frey, B. S., \& Pommerehne, W. W. (1989). Muses and markets. explorations in the economics of the arts. Oxford: Blackwell.

Frey, B. S., \& Stutzer, A. (2000). Happiness, economy and institutions. The Economic Journal, 110(466), 918938.

Galloway, S. (2006). Cultural participation and individual quality of life: A review of research findings. Applied Research in Quality of Life; the Official Journal of the International Society for Quality-ofLife Studies, 1(3), 323-342. doi:10.1007/s11482-007-9024-4

Grossi, E., Tavano Blessi, G., Sacco, P. L., \& Buscema, M. (2012). The interaction between culture, health and psychological well-being: Data mining from the Italian culture and well-being project. Journal of Happiness Studies, 13(1), 129-148. https://doi.org/1007/s10902-011-9254-x

Gruber, M.Challenges and opportunities for decent work in the culture and media sectors.. Geneva: International Labor Organization. Retrieved from https://www.ilo.org/wcmsp5/groups/public/---ed_dialogue/--sector/documents/publication/wcms_661953.pdf

Helliwell, J. F., \& Huang, H. (2008). How's your government? International evidence linking good government and well-being. British Journal of Political Science, 38(4), 595-619. https://doi.org/10.1017/S0007123408000306

Hetland, L. (2000). Listening to music enhances spatial-temporal reasoning: Evidence for the "Mozart effect". Journal of Aesthetic Education, 34(3), 105-148. https://doi.org/10.2307/3333640

Hetland, L., \& Winner, E. (2001). The arts and academic achievement: What the evidence shows. Arts Education Policy Review, 102(5), 3-6. https://doi.org/10.1080/10632910109600008

Kenny, D., Driscoll, T., \& Ackermann, B. Is playing in the pit really the pits?: Pain, strength, music performance anxiety, and workplace satisfaction in professional musicians in stage, pit, and combined stage/pit orchestras. Medical Problems of Performing Artists., (31), 1-7. doi:10.21091/mppa.2016.1001

Karttunen, S. (1998). How to identify artists? Defining the population for 'status-of-the-artist' studies. Poetics, 26(1), 1-19. https://doi.org/10.1016/S0304-422X(98)00007-2

Laitio, T. (2012). Counting what counts. Report on the culture watch Europe. Paper presented at the Cultural Access and Participation - from Indicators to Policies for Democracy. Resource Document. Culture Watch Europe. https://rm.coe.int/16806a34cd. Accessed 22 April 2020.

Lena, J. C., \& Lindemann, D. J. (2014). Who is an artist? new data for an old question. Poetics, 43(1), 70-85. https://doi.org/10.1016/j.poetic.2014.01.001

Long, C. R., \& Averill, J. R. (2003). Solitude: An exploration of benefits of being alone. Journal for the Theory of Social Behaviour, 33(1), 21-44. doi:10.1111/1468-5914.00204

Michalos, A. C. (2005). Arts and the quality of life: An exploratory study. Social Indicators Research, 71(1), 11-59. doi:10.1007/s11205-004-8013-3

Ministry for Finance, (. (2017). National Reform Programme. Malta: Ministry for Finance.

Mitchell, R., \& Karttunen, S. (1992). Why and how to define an artist: Types of definitions and their implications for empirical research results. In R. Towse, \& A. Khakee (Eds.), Cultural Economics (pp. 175-185). Berlin: Heidelberg.

National Statistics Office (NSO), (2012). Culture participation survey 2011. Malta: National Statistics Office. National Statistics Office (NSO), (2017). Culture participation survey 2016. Malta: National Statistics Office. Netz, Y., Wu, M., Becker, B. J., \& Tenenbaum, G. (2005). Physical activity and psychological well-being in advanced age: A meta-analysis of intervention studies. Psychology and Aging, 20(2), 272-284. https://doi.org/10.1037/0882-7974.20.2.272

Parliamentary Secretariat for Tourism, the Environment and Culture (PSTEC) (2011). National Cultural Policy. Malta: Parliamentary Secretariat for Tourism, the Environment and Culture. Resource Document. Parliamentary Secretariat for Tourism, the Environment and Culture. https://www.artscouncilmalta.org/files/uploads/misc/POLICY\%20ENG\%202011\%209\%20jun\%20low \%20res\%20.pdf. Accessed 22 April 2020. 
Perkins, R., Reid, H., Araújo, L.S., Clark, T., \& Williamon, A. (2017). Perceived enablers and barriers to optimal health among music students: A qualitative study in the music conservatoire setting. Frontiers in Psychology, 8, 968. doi:10.3389/fpsyg.2017.00968

Phinney, A., Moody, E. M., \& Small, J. A. (2014). The effect of a community-engaged arts program on older adults' well-being. Canadian Journal on Aging / La Revue Canadienne Du Vieillissement, 33(3), 336345. https://doi.org/10.1017/S071498081400018X

Robb, A. E., Due, C., \& Venning, A. (2018). Exploring psychological wellbeing in a sample of Australian actors. Australian Psychologist, 53(1), 77-86. doi:10.1111/ap.12221

Schulz, W., Hametner, K., \& Wroblewski, A. (1997). Thema kunst: Zur sozialen und ökonomischen lage der bildenden künstler und KünstlerInnen in österreich [Theme art: Concerning the social and economic situation of fine artists in Austria]. Vienna: Falter Verlag.

Stack, S. (2010). Suicide among artists. The Journal of Social Psychology, 137(1), 129-130. https://doi.org/10.1080/00224549709595421

Stark, R., \& Maier, J. (2008). Faith and happiness. Review of Religious Research, 50(1), 120-125.

Steiner, L., \& Schneider, L. (2013). The happy artist: An empirical application of the work-preference model. Journal of Cultural Economics, 37(2), 225-246.

Stuckey, H. L., \& Nobel, J. (2010). The connection between art, healing, and public health: A review of current literature. American Journal of Public Health, 100(2), 254-263.

Towse, R. (1996). The economics of artists' labour markets: ACE research report. London: The Arts Council of England.

UNESCO. (1980). Recommendation concerning the status of the artist. UNESCO. https://en.unesco.org/creativity/governance/status-artist. Accessed 22 April 2020.

UNESCO. (2009). Measuring cultural participation. Canada: UNESCO Institute for Statistics. https://unesdoc.unesco.org/ark:/48223/pf0000219213. Accessed 22 April 2020.

UNESCO. (2019). Culture \& working conditions for artists. Paris: United Nations Educational, Scientific and Cultural Organization. Retrieved from https://unesdoc.unesco.org/ark:/48223/pf0000371790

Waddell, C. (1998). Creativity and mental illness: Is there a link? The Canadian Journal of Psychiatry, 43(2), 166-172. https://doi.org/10.1177/070674379804300206

Walker C; Scott-Melnyk. S, \& Sherwood. K. (2002). Reggae to Rachmaninoff - How and why people participate in arts and culture. The Urban Institute. http://webarchive.urban.org/publications/310595.html 